\title{
Evaluation of inner segment/outer segment junctions in different types of epiretinal membranes
}

\author{
Avaliação da junção segmento interno/segmento externo em diferentes graus de membranas epirretinianas
}

Rukiye Aydin ${ }^{1}$, Eyyup Karahan ${ }^{2}$, Mahmut Kaya 3 , Taylan Ozturk 3 , Kubra Serefoglu Cabuk ${ }^{4}$, Nilufer Kocak ${ }^{3}$, Suleyman Kaynak ${ }^{3}$

\begin{abstract}
Purpose: This study was conducted to evaluate the relationships of inner/outer segment (IS/OS) junction disruption, macular thickness, and epiretinal membrane (ERM) grade with best-corrected visual acuity (BCVA), as well as the relationship between IS/OS junction disruption and ERM grade.

Methods: Fifty-four eyes of 54 patients with different grades of ERM were retrospectively reviewed. Patients were classified into three groups by ERM grade according to retinal striae and vessel distortion: grade/group 1, visible membranes withou retinal striae or vessel distortion; grade/group 2, mild to moderate macular striae or vessel straightening; and grade/group 3, moderate to severe striae and vascula straightening. Correlations of BCVA with age, central retinal thickness, ERM grade, and IS/OS disruption as well as of IS/OS disruption, central macular thickness, and BCVA with ERM grade were evaluated.

Results: Twenty-nine (53.7\%) eyes exhibited IS/OS junction disruption. Groups 1 and 2 differed significantly with respect to BCVA ( $p=0.038)$, but groups 2 and 3 did not $(p=0.070)$. Central macular thickness was significantly greater in group 2 than in group $1(p=0.031)$ and in group 3 than in group $2(p=0.033)$. Groups 1 and 2 differed significantly in terms of IS/OS disruption ( $p=0.000)$, but groups 2 and 3 did not $(p=0.310)$.

Conclusions: The IS/OS junction appears to be disrupted during the early stages of ERM. Grade 3 ERM is associated with a significantly higher incidence of IS/OS
\end{abstract} disruption.

Keywords: Epiretinal membrane; Retinal photoreceptor cell inner segment; Diagnostic techniques, ophthalmologic; Tomography, optical coherence/methods

\section{RESUMO}

Objetivo: Este estudo foi realizado para avaliar a relação entre a interrupção da junção segmento interno/segmento externo (IS/OS), espessura macular e grau de membrana epirretiniana (ERM), com a melhor acuidade visual corrigida (BCVA), e a relação entre a interrupção da junção IS/OS com a severidade da ERM.

Métodos: Cinquenta e quatro olhos de 54 pacientes com diferentes graus de ERM foram avaliados retrospectivamente. ERMs foram classificadas, de acordo com as estrias de retina e a distorção dos vasos, em 3 grupos: grupo 1 foram membranas visíveis sem estrias retinianas ou distorção dos vasos, grupo 2 membranas com estrias maculares discretas a moderadas ou retificação dos vasos, e grupo 3 membranas com estrias moderadas a graves e retificação vascular. A correlação da BCVA com a idade, espessura central da retina, severidade da ERM e interrupção da junção IS/OS foram avaliadas. A relação de interrupção da junção IS/OS, a espessura macular central e acuidade visual com a severidade da ERM também foram avaliadas.

Resultados: Vinte e nove olhos (53,7\%) apresentavam interrupção da junção IS/OS. A BCVA foi diferente entre ERMs grupo 1 e grupo $2(p=0,038)$, a diferença entre o grupos 2 e 3 não foi estatisticamente significativa $(p=0,070)$. A espessura macular central foi estatisticamente maior no grupo 2, quando comparado ao grupo $1(p=0,031)$ e maior no grupo 3 quando comparado ao grupo $2(p=0,033)$. A diferença entre o grupo $1 \mathrm{e}$ grupo 2 em relação à interrupção da junção IS/OS foi estatisticamente significativa $(p=0,000)$, ao passo que a diferença entre o grupo 2 e do grupo 3 não foi estatisticamente significativa $(p=0,310)$.

Conclusões: As junções IS/OS parecem estar interrompidas nos estágios iniciais da ERM. O grau 3 de ERM têm uma maior incidência significativa de interrupção da junção IS/OS.

Descritores: Membrana epirretiniana; Segmento interno das células fotorreceptoras da retina; Técnicas de diagnóstico oftalmológico; Tomografia de coerência óptica

\section{INTRODUCTION}

Epiretinal membrane (ERM) is a type of nonvascular fibrocellular proliferation that develops on the surface of the internal limiting membrane and causes retinal wrinkling and distortion. Spectral domain optical coherence tomography (SD-OCT) has yielded unprecedented details about ERM, the retinal structure, the overlying vitreous layer, and has reliably resolved details of individual retinal layers ${ }^{(1-3)}$ One layer that is clearly delineated by SD-OCT represents the junction between the photoreceptor's inner and outer segments (IS/OS junction). In normal eyes, this junction is visible as a hyperreflective line immediately above the retinal pigment epithelium. Disruption of this layer reflects an anatomical disruption of the retinal photoreceptors ${ }^{(4,5)}$. Studies involving SD-OCT in patients with ERM have shown that visual acuity deteriorates as a result of IS/OS junction disruption ${ }^{(6-10)}$, and that there is thickening of the central macula ${ }^{(8-12)}$ and outer retina ${ }^{(11,12)}$. In support of this, Oster et al. ${ }^{(13)}$ found that the IS/OS junction was a more useful predictor of poor visual acuity when compared with central macular thickness.

Currently, both preoperative and postoperative IS/OS disruption are known to lead to visual acuity deterioration in eyes with ERM; however, very little information is currently available about the relationship between IS/OS disruption and the ERM grade. Furthermore,
Submitted for publication: February 2, 2016

Accepted for publication: May 15, 2016

${ }^{1}$ Department of Ophthalmology, Faculty of Medicine, Medipol University, Istanbul, Turkey.

Department of Ophthalmology, Faculty of Medicine, Sifa University, Izmir, Turkey.

${ }^{3}$ Department of Ophthalmology, Faculty of Medicine, Dokuz Eylul University, Izmir, Turkey.

${ }^{4}$ Department of Ophthalmology, Bağcılar Training and Research Hospital, Istanbul, Turkey.
Funding: No specific financial support was available for this study.

Disclosure of potential conflicts of interest: None of the authors have any potential conflicts of interest to disclose.

Corresponding author: Mahmut Kaya. Mithatpasa Cad. 2. Karatas, № 338, D:12 - Konak, Izmir Turkey-E-mail: mahmutkaya78@yahoo.com

Approved by the following research ethics committee: Istanbul Medipol University Research Ethics Committee (\#264/2015). 
the ERM grade during which IS/OS disruption begins has yet to be discerned. In this study, we evaluated the relationships of IS/OS disruption, macular thickness, and ERM grade with visual acuity. Additionally, we evaluated the relationship between IS/OS disruption and ERM grade.

\section{METHODS}

Data of patients with different ERM grades who had undergone SD-OCT scanning (HRA-2; Heidelberg Engineering, Heidelberg, Germany) were retrospectively reviewed, in accordance with the tenets of the Declaration of Helsinki. Only patients with primary ERM were included in the study. We excluded patients with primary vitrectomy and ocular disorders associated with ERM, such as uveitis, and patients with macular disorders and/or significant cataracts that blocked the visualization of ERM during fundoscopy and SD-OCT scans. The final study group was comprised of a total of 54 eyes of 54 patients. We obtained each patient's age, sex, and best-corrected visual acuity (BCVA) from medical records.

All patients underwent SD-OCT evaluations involving horizontal and vertical scans performed at maximal resolution through the fovea. Patients also underwent fundus imaging via color fundus photography (Topcon, Paramus, NJ, USA) to visualize details of the fundus. For each patient, the ERM severity was graded on fundus images using a three-step scale as described previously ${ }^{(13)}$. Grades 1, 2, and 3 ERM were defined as a visible membrane without retinal striae or vessel distortion, mild to moderate macular striae or vessel straightening, and moderate to severe striae and vascular straightening, respectively (Figure 1 A, B, and C, respectively). A single observer (S.K.) who was blinded to the visual acuity and SD-OCT scan data graded all fundus images.
Next, we measured several variables from the SD-OCT images. Foveal thickness, which was calculated using a caliper feature on the SD-OCT instrument with manual correction as needed, was determined as an average of the values from both horizontal and vertical scans. The photoreceptor IS/OS layer was evaluated for $500 \mu \mathrm{m}$ in either direction of the fovea on both horizontal and vertical scans, and a diagnosis of a disrupted IS/OS junction was based on the absence and/or irregularity of the aforementioned hyperreflective line (Figure 2 A, B). One observer (R.A.), who was blinded to the clinical findings of the patients (e.g., visual acuity and ERM grade), measured the retinal layer thickness and assessed the status of the IS/OS junction.

Correlations of BCVA with age, central retinal thickness, ERM grade, and IS/OS disruption were evaluated using linear regression analysis. In addition, eyes were divided into three groups with respect to ERM grade: group 1, eighteen (33.3\%) eyes with grade 1 ERM; group 2, 21 (38.9\%) eyes with grade 2 ERM; and group 3, 15 (27.8\%) eyes with grade 3 ERM. The relationships of IS/OS disruption, central macular thickness, and BCVA with the ERM grade were also evaluated through linear regression analysis.

\section{Statistical analysis}

SPSS version 11.6 (SPSS, Inc., Chicago, IL, USA) was used for the statistical analysis. Visual acuity values weres converted to logMAR units for the statistical analyses. In addition to the linear regression analyses mentioned above, a one-way analysis of variance with a post-hoc Tukey's test was used to compare the three groups with respect to BCVA and central macular thickness. Categorical variables were compared between the groups with the $\chi^{2}$ test. A P value $<0.05$ was considered statistically significant.
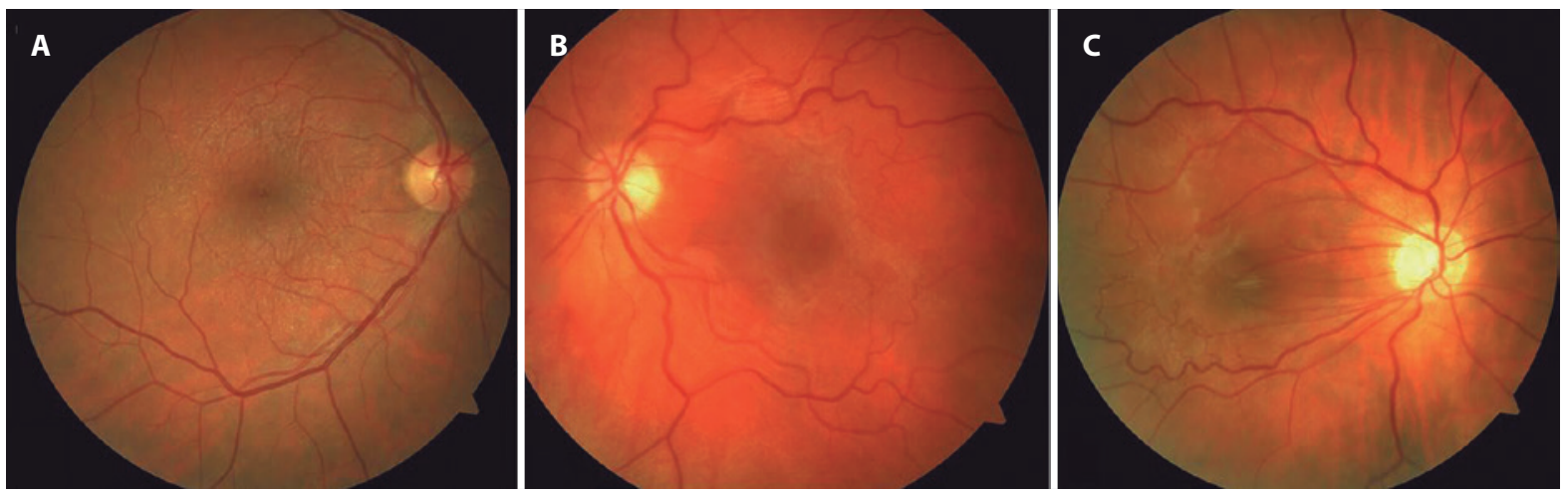

Figure 1. Fundus grading of the epiretinal membrane (ERM). A) Example of a grade 1 ERM with minimal retinal surface changes. B) Early macular striae are visible in a grade 2 ERM. C) A combination of large macular striae and prominent vascular straightening are seen in a grade 3 ERM.
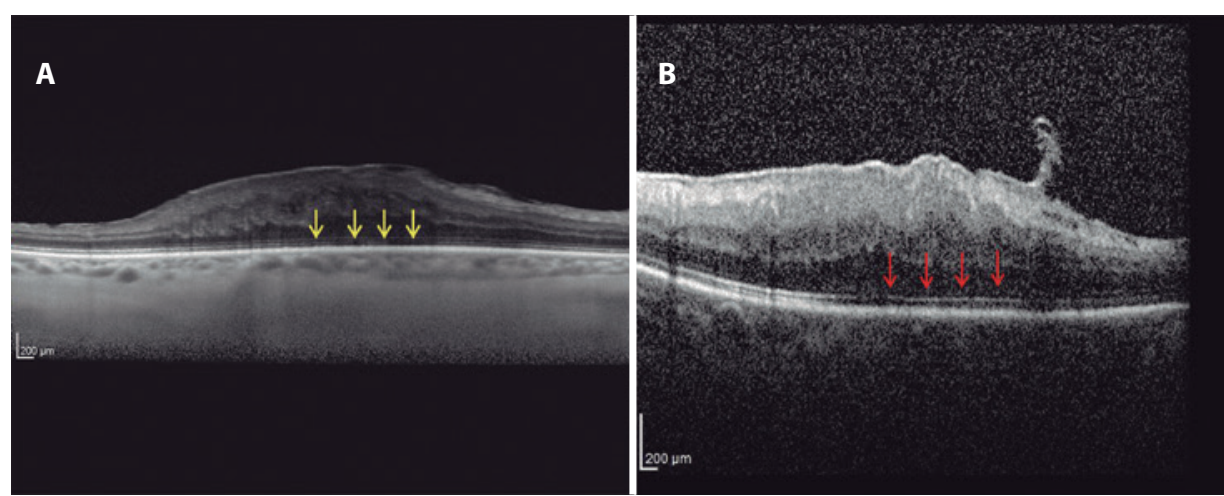

Figure 2. A) Example of an intact inner segment/outer segment (IS/OS) junction. B) Example of a disrupted IS/OS junction (arrow). 


\section{RESULTS}

Of the 54 patients, 20 (37.0\%) were men and 34 (63.0\%) were women. The mean age of the patients was 67.9 \pm 9.2 years (range: $41-84$ years). In addition, the mean logMAR visual acuity and mean central retinal thickness were $0.4 \pm 0.32$ (range: $0.0-2.0$ ) and $462.6 \pm 119.8 \mu \mathrm{m}$ (range: 271-877 $\mu \mathrm{m})$, respectively. Twenty-nine (53.7\%) of the eyes exhibited IS/OS disruption. Notably, the correlation of age with BCVA was not significant $\left(r^{2}=0.018, p=0.334\right)$. However, BCVA exhibited significant correlations with central retinal thickness $\left(r^{2}=0.531, p=0.000\right)$, IS $/ O S$ disruption $\left(r^{2}=0.304, p=0.000\right)$, and ERM grade $\left(r^{2}=0.287, p=0.000\right)$. The characteristics and clinical data of the patients are shown in table 1.

The three groups, stratified according to ERM grade, were compared with respect to age, sex, BCVA, central macular thickness, and IS/OS disruption. Age and sex were found to be similar among the groups ( $p=0.519$ and $p=0.300$, respectively). In terms of $B C V A$, groups 1 and 2 differed significantly $(p=0.038)$, whereas the difference between groups 2 and 3 was not statistically significant $(p=0.070)$. Central macular thickness was significantly greater in group 2 compared to group 1 ( $p=0.031$ ) and in group 3 compared to group 2 ( $p=0.033)$.

IS/OS distortion was observed in two (11.1\%) of the eyes in group $1,14(66.7 \%)$ of the eyes in group 2, and 13 (86.7 \%) of the eyes in group 3. The difference in IS/OS disruption between groups 1 and 2 was found to be statistically significant $(p=0.000)$, whereas the difference between groups 2 and 3 was not significant $(p=0.310)$. Characteristics of the three groups are shown in table 2.

\section{DISCUSSION}

Retinal traction caused by an ERM leads to morphological changes that affect the entire retina, including the photoreceptor layer, rather than merely the superficial layers. This characteristic is important be-

Table 1. Characteristics of patients classified according to epiretinal membrane grade

\begin{tabular}{|c|c|c|c|c|}
\hline & Group $1(n=18)$ & Group $2(n=21)$ & Group $3(n=15)$ & $P$ value \\
\hline Age (years) & $66.20 \pm 11.20$ & $67.80 \pm 8.50$ & $70.00 \pm 7.50$ & 0.519 \\
\hline \multicolumn{5}{|l|}{$\operatorname{Sex}(\%)$} \\
\hline Male/female & $37.8 / 62.2$ & $33.3 / 66.7$ & $41.70 / 58.30$ & 0.300 \\
\hline BCVA & $0.20 \pm 0.14$ & $0.42 \pm 0.22$ & $0.64 \pm 0.43$ & $0.000^{*}$ \\
\hline $\mathrm{CMT}(\mu \mathrm{m})$ & $383.20 \pm 81.60$ & $465.50 \pm 87.10$ & $554.00 \pm 135.60$ & $0.000^{*}$ \\
\hline
\end{tabular}

IS/OS junction (\%)

$\begin{array}{lllll}\text { Disrupted/Intact } & 11.1 / 88.9 & 66.7 / 33.3 & 86.70 / 13.30 & 0.000^{*}\end{array}$

*=statistically significant; $\mathrm{BCVA}=$ best-corrected visual acuity; $\mathrm{CMT}=$ central macular thickness; IS/OS= inner segment/outer segment.

Table 2. Comparison of BCVA, CMT, and IS/OS disruption between groups

\begin{tabular}{lcc}
\hline & Mean & P value \\
\hline BCVA (logMAR) & $0.20 \pm 0.14-0.42 \pm 0.22$ & 0.038 \\
Group 1 - Group 2 & $0.42 \pm 0.22-0.64 \pm 0.43$ & 0.070 \\
Group 2 - Group 3 & \\
CMT ( $\mu$ m) & $383.2 \pm 81.6-465.5 \pm 87.1$ & $0.031^{*}$ \\
Group 1 - Group 2 & $465.5 \pm 87.1-554.0 \pm 135.6$ & $0.033^{*}$ \\
Group 2 - Group 3 & $11.1-66.7$ & \\
Disrupted IS/OS junction (\%) & $66.7-86.7$ & $0.000^{*}$ \\
Group 1 - Group 2 & 0.310 \\
Group 2 - Group 3 & & \\
\hline
\end{tabular}

*= statistically significant; $B C V A=$ best-corrected visual acuity; $C M T=$ central macular thickness; IS/OS= inner segment/outer segment. cause longstanding morphological changes in the retina can lead to irreversible functional damage. Extensive studies of the integrity of the photoreceptor IS/OS line have demonstrated a significant association between an intact IS/OS line and better postoperative BCVA after successful removal of an $\mathrm{ERM}^{(6,7,10,14)}$. Inoue et al ${ }^{(6)}$ evaluated the prognostic value of IS/OS line integrity and observed significantly better postoperative BCVA in patients with an intact IS/OS junction pre-operation. Furthermore, using preoperative SD-OCT scans, Cobos et al. ${ }^{(15)}$ observed significantly better postoperative BCVA in eyes with an intact IS/OS junction, compared to eyes with an irregular or disrupted IS/OS junction.

In another study of 41 patients who underwent surgery for ERM, potential prognostic factors that may influence functional outcomes were investigated. Notably, the baseline CRT and appearance of the foveal contour did not significantly influence distance and near visual acuity outcomes at 3-month follow-up. However, patients with a continuous or interrupted IS/OS line exhibited significant improvements in distance and near visual acuity at 3 months, as well as a significantly higher rate of improvements in both distance and near visual acuity, compared to patients with a nearly absent IS/OS line ${ }^{(7)}$. Suh et al. ${ }^{(8)}$ evaluated 101 eyes of 101 patients with idiopathic ERM who underwent PPV for ERM removal. OCT-detected photoreceptor disruption, which was potentially irreversible, was found to be a good predictor of poor visual outcomes in eyes with idiopathic ERM. The authors postulated that early membrane removal might prevent additional photoreceptor damage in ERM patients with photoreceptor disruption. In the present study, the central macular thickness increased significantly as the ERM grade increased. In addition, differences in IS/OS disruption rates and BVCA were only significant between patients with grade 1 and grade 2 ERM. We believe that these findings suggest the presence of IS/OS disruption, even at early stages of ERM, and indicate that the main disruption occurs between grades 1 and 2 .

Mitamura et al. ${ }^{(10)}$ used OCT to evaluate 70 eyes of 70 consecutive patients who underwent vitrectomy for idiopathic ERM; evaluations were conducted before and at 3 and 6 months after surgery. In that study, the preoperative IS/OS junction grade correlated significantly with BCVA at 6 months. However, central foveal thickness did not correlate with BCVA between 3 and 6 months. Massin et al. ${ }^{(16)}$ also reported that the preoperative macular thickness did not correlate with the postoperative BCVA. In our study, the correlation of CMT with BCVA was stronger than the correlation of IS/OS with BCVA. Interestingly, the IS/OS disruption rate and mean BCVA did not differ between grade 2 and 3 ERMs, whereas the mean CMT was higher in grade 3 ERMs relative to grade 2 ERMs.

Suh et al. ${ }^{(8)}$ reported that 12 of 37 eyes (32.40\%) with a postoperatively disrupted IS/OS junction possessed an intact preoperative IS/OS junction; in contrast, only 5 of the 64 eyes (7.81\%) with an intact IS/OS junction exhibited a preoperatively disrupted IS/OS junction. As we think that IS/OS disruption begins during the early stages of ERM, we suggest that early membrane removal should be considered to prevent additional photoreceptor damage in patients with ERM.

We must note some limitations of the present study. Notably, the study featured a retrospective design and lacked a control group. In addition, only a small number of patients were included, and this might have affected the reliability of the statistical analysis.

In conclusion, the IS/OS junction appears to be disrupted during the early stages of ERMs. Grade 3 ERMs had a significantly higher incidence of IS/OS disruption, a finding that suggested by the poorer surgical outcomes reported in other studies. Future prospective studies with larger sample sizes are needed to determine the relationship between the IS/OS junction and ERM development.

\section{REFERENCES}

1. Legarreta JE, Gregori G, Knighton RW, Punjabi OS, Lalwani GA, Puliafito CA. Three-dimensional spectral-domain optical coherence tomography images of the retina in the presence of epiretinal membranes. Am J Ophthalmol. 2008;145(6):1023-30.

2. Koizumi H, Spaide RF, Fisher YL, Freund KB, Klancnik JM Jr, Yannuzzi LA. Three-dimensional 
evaluation of vitreomacular traction and epiretinal membrane using spectral-domain optical coherence tomography. Am J Ophthalmol. 2008:145(3):509-17.

3. Marmor MF, Choi SS, Zawadzki RJ, Werner JS. Visual insignificance of the foveal pit: reassessment of foveal hypoplasia as fovea plana. Arch Ophthalmol. 2008;126(7):907-13.

4. Inoue M, Watanabe Y, Arakawa A, Sato S, Kobayashi S, Kadonosono K. Spectral-domain optical coherence tomography images of inner/outer segment junctions and macular hole surgery outcomes. Graefes Arch Clin Exp Ophthalmol. 2009;247(3):325-30.

5. Baba T, Yamamoto S, Arai M, Arai E, Sugawara T, Mitamura Y, et al. Correlation of visual recovery and presence of photoreceptor inner/outer segment junction in optical coherence images after successful macular hole repair. Retina. 2008;28(3):453-8.

6. Inoue M, Morita S, Watanabe Y, Kaneko T, Yamane S, Kobayashi S, et al. Inner segment/ outer segment junction assessed by spectral-domain optical coherence tomography in patients with idiopathic epiretinal membrane. Am J Ophthalmol. 2010;150(6):834-9.

7. Falkner-Radler Cl, Glittenberg C, Hagen S, Benesch T, Binder S. Spectral-domain optical coherence tomography for monitoring epiretinal membrane surgery. Ophthalmology. 2010;117(4):798-805.

8. Suh MH, Seo JM, Park KH, Yu HG. Associations between macular findings by optical coherence tomography and visual outcomes after epiretinal membrane removal. Am J Ophthalmol. 2009;147(3):473-80.

9. Michalewski J, Michalewska Z, Cisiecki S, Nawrocki J. Morphologically functional correlations of macular pathology connected with epiretinal membrane formation in spectral optical coherence tomography. Graefes Arch Clin Exp Ophthalmol. 2007;245(11): $1623-3$
10. Mitamura Y, Hirano K, Baba T, Yamamoto S. Correlation of visual recovery with presence of photoreceptor inner/outer segment junction in optical coherence images after epiretinal membrane surgery. Br J Ophthalmol. 2009;93(2):171-5.

11. Watanabe A, Arimoto S, Nishi O. Correlation between metamorphopsia and epiretinal membrane optical coherence tomography findings. Ophthalmology. 2009;116(9): 1788-93

12. Arichika S, Hangai M, Yoshimura N. Correlation between thickening of the inner and outer retina and visual acuity in patients with epiretinal membrane. Retina. 2010;30(3): 503-8.

13. Oster SF, Mojana F, Brar M, Yuson RM, Cheng L, Freeman WR. Disruption of the photoreceptor inner segment/outer segment layer on spectral domain-optical coherence tomography is a predictor of poor visual acuity in patients with epiretinal membranes. Retina. 2010;30(5):713-8

14. Kim JH, Kim YM, Chung EJ, Lee SY, Koh HJ. Structural and functional predictors of visual outcome of epiretinal membrane surgery. Am J Ophthalmol. 2012:153(1):103-10.

15. Cobos E, Arias L, Ruiz-MorenO JM, Rubio MJ, Garcia-Bru P, Caminal JM, et al. Preoperative study of the inner segment/outer segment junction of photoreceptors by spectral-domain optical coherence tomography as a prognostic factor in patients with epiretinal membranes. Clin Ophthalmol. 2013;7:1467-70.

16. Massin P, Allouch C, Haouchine B, Metge F, Paques M, Tangui L, et al. Optical coherence tomography of idiopathic macular epiretinal membranes before and after surgery. Am J Ophthalmol. 2000;130(6):732-9.

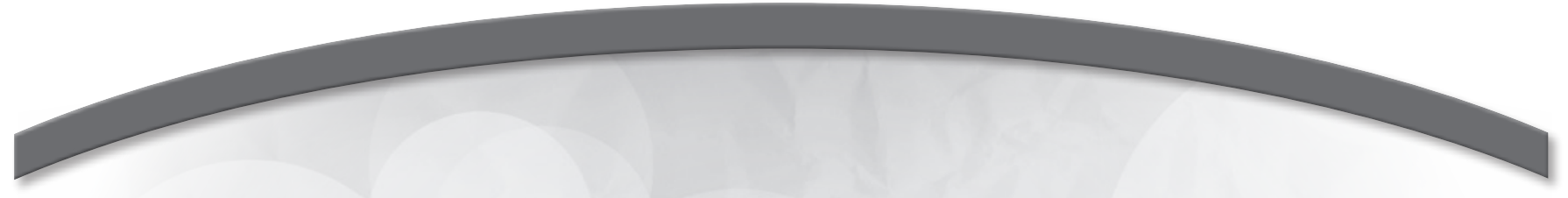

IV Congresso Internacional de Estética Periocular XXV Congresso Internacional de Oculoplástica

\author{
29 de abril a 10 de maio de 2017 \\ Centro de Convenções do Hotel Mercure BH Lourdes \\ Belo Horizonte - MG
}

\title{
Informações:
}

E-mail: congressosbcpo@consulteventos.com.br Site: www.sbcpocongressos.com.br 